Advanced Computing: An International Journal (ACIJ), Vol.7, No.4/5/6, November 2016

\title{
E-LEARNING FOR ALL WITH INTERFACE INCORPORATING KNOWLEDGE ABOUT USER
}

\author{
IRENE TIAKO $^{1}$, ELIANE KOUEDE $^{2}$ and Pierre Tiako ${ }^{3}$ \\ ${ }^{1}$ ENSP, University of Yaoundé I, Yaoundé, Cameroon \\ ${ }^{2}$ Faculty of Science, University of Yaoundé 1, Yaoundé, Cameroon \\ ${ }^{3}$ CITRD, Tiako University, Oklahoma, USA
}

\begin{abstract}
The rapid development of Information and Communication Technologies (ICT) is an asset for e-learning. This is a new form of distance education that relies on the Internet and the Web. This new pedagogical approach promote that the learner is the protagonist of his/her own training and thereby put in range that he/she needs to complete his/her apprenticeship. These resources are made available on the platform by the trainers. Unfortunately, in the majority of e-learning platforms, the course is offered, regardless of the state of the learner (disability, level of education, age, etc ...). Many people thus excluded from e-learning. This somewhat mitigates e-learning possibilities. According to world statistics, $10 \%$ of the world population, about 650 million people, lives with disability [1]. The promotion of employment for all, advocated by human rights, will dwell on this mode of learning to train all young people who for many reasons do not always have the opportunity to attend a campus training center. E-learning should also be available to disable persons such as blinds, deafs, mutes,... This work develops new interfaces that adapt according to knowledges of the learner to facilitate e-learning. The illiteracy rate is therefore reduce in its simplest form.
\end{abstract}

\section{KEYWORDS}

E-learning, Pedagogical Approach, Online Education, Information Technology and Communication (ICT), Vocational Training Center, Campus training, Knowledge of the Learner.

\section{INTRODUCTION}

E-learning or online learning helps remedy the campus training issue, giving it a very important place in vocational training firms and centers, which can now use it to increase the number of learners. With the arrival of the Information Technology and Communication for Education (ITCE), we will propose an approach of e-learning for all those who want to learn online. The creation of an authorized training center requires a lot of resources. Communities not having enough resources to create their training centers will train their people on such platform we are proposing. Vocational training is the set of measures adopted for the acquisition or development of a professional qualification. That training teaches the knowledge to provide the necessary skills to execute a function, employment or occupation.

Anyone (employees, students, the disabled, prisoners) may benefit from professional training through the use of our proposed e-learning platform. In such platform, course materials and manuals for practical work of each sector will be deposited. However, they may be acquired through diversified courses online if they are diploma awarding or not. The objective of this platform is:

DOI:10.5121/acij.2016.7601 
1 - to offer people skilled training for insertion into the economy;

2 - to fight against poverty and to promote the employability of all layers of the population.

The methodology is based on the ADDIE model (Analysis Design Development Implementation Evaluation) [4]. We want to implement a knowledge base system where all the academics programs, trainers, learners and courses will be recorded. Learners will give their details, and interfaces that will suit will be available for training. For a learner visually impaired, the system will deduct and display a course with large print or audio course, more friendly to him/her. Learners will have the opportunity to take their courses, either audio or video. Each learner will be able to choose the area that suits him/her and identify with. The state of the learner is taken into account at the registration time on the platform. An important contribution is that the system can also deduct certain knowledge of the learner, such as it is asleep, tired. When connected the system automatically records the start time, after a period of inactivity, a ringing can be triggered to wake up the learner if he/she falls asleep or acts tired. This is an innovation in e-learning mechanisms. We will emphasize on the aspects that influence the understanding of the lesson to know: what is the background of the home page, the image or images that are on the page, size or color of the font that could interest such player in the system (learner, trainer). The client / server architecture will be adopted because users, who connect to the platform, once they have an account, will be directed to the space they deserve. The e-learning standards adopted in this paper are standards published by standardization bodies such as AFNOR and ISO [24]. The standard used is ISO/IEC 10780-1, standard confirmed on 27/10/2005 that emphasizes a collaborative and communicative learning [14]. We will do an inventory of e-learning places in the first part of this paper. In the second part we will begin the design. The development itself will be in third part. Implementation is the contents of the fourth part. An evaluation will follow in the fifth game and then we will end up with the conclusion and prospects.

\section{State Of The Art And Related Work}

\subsection{Definitions And General Information On E-Learning Platforms}

European Commission defines E-learning as the: "use of new multimedia technologies and the Internet to improve the quality of learning by facilitating access to resources and services, as well as exchange and remote collaboration" [25].

E-Learning therefore is the combination of interactive and multimedia, distribution media (PC, internet, intranet, extranet), a set of software tools that enable the management of online training and creation of interactive training tools. Access to resources is considerably expanded as opportunities for collaboration and interactivity[7]. E-learning is originally a subset of ODL (Open Distance Learning), which relies on electronic networks. Today the concept of e-learning is increasingly used, attesting to the fundamental evolution of the training field. Online learning is defined as: " learning mode based on the use of new technologies, which allows access to online training, interactive and sometimes customized, distributed via Internet, intranet or other electronic media, to develop skills, while making the learning process independent of time and place " [13].

\subsection{Status Of The Problem}

Several distance trainings such as those provided by the Agence Universitaire de la Francophonie (AUF) [16] do not give an opportunity for the mentally disabled, visual, auditory, ... to fully benefit from this training [31]. Yet this part of the population has a potential that can wake up with a well calibrated distance education. The major problems which we face are the lack of infrastructure, at this time they are not enough classrooms for all learners. The people are very 
poor to paid tuition fees. So those people are not educated and have just to stay home. According to United Nations, among seventeen objectives to transform the world, the education quality is listed [32].

\subsection{The Growth Of ICT AND E-Learning In The WorLd.}

The online training market has found its bearings. Companies, universities, high schools and elearning tool suppliers are now fully aligned. E-learning has evolved from a supply market to a demand market. Furthermore several organizations, businesses and structures have focused on ICT at the service of education and training. This is one reason why the e-learning stabilizes. Many people worldwide are moving increasingly towards e-learning because teaching has taken precedence over technology.

We will quote the famous Zero site now become openclassroom, which brings together thousands of people around the world with diverse academic programs, the address is: www.openclassroom.com.

\subsection{RELATED WORK AND LIMITATIONS.}

Several names are assigned to online training platforms: LMS, CMS, LCMS, C3MS and LKMS.

- LMS (Learning Management System) is a web course management system that enables learners, through a browser to access courses provided by teachers [9]. Ganesha, Claroline, Moodle, and Sakai Dockeos are examples of LMS.

- CMS (Content Management System) is a content management system. It allows publication of multimedia content on a local or remote network. The contents are stored in a knowledge base system. Examples SPIP, Joomla and Typo3 are fairly common content management systems [9].

- LCMS (Learning Content Management System) is an integrated distance learning system using all the features of an LMS and a CMS. It also includes an interface for creating courses. Examples of LCMS are TopClass and SimplyLearn.

- C3MS (Content, Community, and Collaborative Management System) has CMS functions and the inclusion of community assistance [21]. A modular CMS is not very different from C3MS. We quote PostNuke and Moodle as examples of C3MS [28].

- LKMS (Learning Knowledge Management System) is a platform designed by specialists in learning technology and produced by generator TELOS (TeleLearning Operating System): it is a Web portal generator supporting learning and knowledge management. The realization of a LKMS in a particular context is called LKMA (Learning Knowledge Management Application). Each LKMA has different environments depending on the role played by the user [2]. This platform is similar to the one we intend to develop. We place special emphasis on illustration. Thus, a learner who wants to make in the fields of Beauty for instance, will have a background with images of well-designed multimedia specialists to be more comfortable, it is not the case for a learner making in Agricultural Businesses for example who needs another type of background.

These platforms have in common:

- Actors (administrators, educators, supervisor ....);

- Communication tools (chat, forums, polls, video conference ....);

- Educational tools (create a duty, lesson, course management, access rights ...);

- Organization of training units: lectures, courses, modules; 
- User management: registration, registration, group, rights monitoring;

- The traceability of activities performed by the learner and statistics;

The learner has everything to complete his/her training, however, the design factor is fundamental to e-learning and should be considered.

The decree on ODL (Open Distance Learning) of the Act of 5 March 2014 on vocational training needs new requirements justification ergonomics and design interface for training. The methodology is blended learning, which is a mix between online learning and learning in the classroom.

We agree with Louise Marchand [15] in her paper "Elearning in Business", that companies that are ahead are companies that adapt both internal and external factors, and thus directs the training of their employees encouraging the birth of new ideas and new concepts. They have understood that knowledge of employees arising from its training is the most important capital of the company. Freeware existing e-Learning like Moodle[28], Claroline [29] do not take into account the psychological characteristics even less physiological of the users. Most platforms have courses focused to dedicated level of study.

\subsection{Comparison Of E-Learning And Traditional Training.}

Table 1. Traditional training and e-learning

\begin{tabular}{|c|c|c|}
\hline & Traditional training & E-learning \\
\hline Strengths & $\begin{array}{l}\text { - Ability to see if the } \\
\text { trainer is on the board } \\
\text { or in training room; } \\
\text {-Collaboration with } \\
\text { other learners; } \\
\text {-Interaction between } \\
\text { the trainer and the } \\
\text { learner. }\end{array}$ & $\begin{array}{l}\text { - Training in a long distance (online learning entirely distance); } \\
\text { - Blended learning (e-learning + learning-face to face with the } \\
\text { instructor); } \\
\text { - Training in synchronous mode: real-time platforms and system of } \\
\text { "virtual classroom"; } \\
\text { - Asynchronously training: trainers and learners communicate via } \\
\text { the platform but not necessarily simultaneously. } \\
\text { Whatever the choice among these online courses as strengths can } \\
\text { be highlighted: } \\
\text { - Strengths: } \\
\text { - Freedom to follow such training; } \\
\text { - Participation of disabled people, the impaired (deaf mute, visually } \\
\text { impaired), prisoners, women and mothers not having a "baby sitter" } \\
\text { and people in conflict zones; } \\
\text { - Ability to train a large number of learners, even geographically } \\
\text { dispersed. } \\
\text { This solution particularly appealing to large corporations, that see } \\
\text { here the way to train many employees at a lower cost. Training } \\
\text { costs are reduced: no travel, no wasted time, no accommodation } \\
\text { costs. The cost of e-learning solution is also less than the hourly } \\
\text { cost of a trainer in a gymnasium. Access to the course is generally } \\
\text { unlimited. }\end{array}$ \\
\hline $\begin{array}{l}\text { Disadvan } \\
\text { tages }\end{array}$ & $\begin{array}{l}\text { - Framed in time; } \\
\text {-People with certain } \\
\text { disabilities (dumb, } \\
\text { evil clairvoyance) are } \\
\text { not always willing to } \\
\text { take the training for } \\
\text { various reasons. }\end{array}$ & $\begin{array}{l}\text { - Equipment that is not always available, computers are not } \\
\text { accessible to the average in developing countries ; } \\
\text { - The non-existent Internet connection, more in some places there is } \\
\text { no electricity; } \\
\text { Given its advantages and disadvantages, e-learning must be used } \\
\text { for specific and limited academic programs, and cannot replace } \\
\text { traditional trainings. }\end{array}$ \\
\hline
\end{tabular}




\subsection{Changes In Teaching ApProaches}

The pedagogical approach is based on the objectives that behaviorism considers that the process of learning is a "response stimuli," the trainer here is the "center" of the learning process: he/she is "the master". The disadvantage here is the low transfer of knowledge to learners. Contrariwise, the new competency-based approach is a positivist and cognitive approach based on constructivism and socio-constructivism. It places the learner at the "center" of the process, it implements four aspects: cognitive, emotional, meta-cognitive and communicative. That is why this approach was chosen.

- Cognitivism initiated by Piaget [18], this model helps understand how man builds, stores, and turns knowledge (cognition) into new one. According to this model, learning is not done by the packaging, but by building new knowledge, based on previously acquired knowledge and interactions with the environment. Thus new knowledge is created by transposition in new situations. The use of this training platform can be achieved in online activities such as problem solving (eg . Cyber investigations) or "serious games".

-Vygotski [23], in his book "Thought and Language", has developed social constructivism. This pedagogical theory states that the trainer is, in fact, a mediator, a guide to knowledge. The real construction of knowledge is primarily the result of interactions with others and the environment. The learner must be at the heart of the construction of knowledge, for it is he/she who must find the way to build knowledge with his/her own experiences in confronting others and the environment.

\section{DESIGN}

The objective of this section is to present the implementation of the proposed platform. The design will be structured as follows: we will define the possible use cases, develop the sequence diagrams, use the class diagram to highlight key points of our platform. UML (Unified Modeling Language) will be used for our design. The qualitative aspect represents all the steps that must be followed for optimal results. These criteria are multiples:

- The validity: it is the ability of the platform to task defined specification;

- Scalability: it is the adaptation of the platform specification to change;

- Integrity: is the ability of the platform to protect its components against unauthorized access or unauthorized modifications;

- Ease of use: it is the ease with which users can access the features of the platform.

\subsection{REQUIREMENTS ANALYSIS}

The most use is the SWOT analysis: Strengths, Weaknesses, Opportunities, Threats. It quickly helps to step back, to see where one starts, identifies the ideal location to reach, and measures the difference between the current level and the desired level[11]. Also known as the SWOT matrix (Strengths Weaknesses Opportunities Threats), which aims to identify opportunities that can contribute to the achievement of objectives. It implements the threats that may compromise the infringement.

Table 2. The SWOT analysis

\begin{tabular}{|l|l|l|}
\hline & Positive & Negative \\
\hline Internally & Strengths & Weaknesses \\
\hline Externally & Opportunities & Threats \\
\hline
\end{tabular}


The strengths of the project

- Internet and documentation;

- Creation of new industries, jobs and need professionalism of young people;

- Several studies on e-learning [12] [16];

- Be informed and learn continuously new technologies and their evolution;

- Great coverage, all cities in the world.

The weaknesses of the project

- Problems with Internet connection;

- Equipment (Laptop, computer desk, video projector ...) are not accessible to everybody;

- Low specialization in e-learning.

Task Analysis: A user is a person who interacts with the system in order to realize a profit. The actors interacting with our system are the Administrator, the Trainer, the Learner, and the Visitor. Each trainer is responsible for one or more courses; the site allows the trainer to file, to update its training manual, publish his/her work practices, MCQ (Multiple Choice Questions) to facilitate understanding of his/her course. The learner is at the center of training, he/she can consult his/her classes; see his/her videos and revise his/her lessons by making multiple choice questions. The administrator is responsible for the installation and maintenance of the system. The visitor is one who consults seminar announcements, industry, training or job offers on the site.

\subsection{KNOWLEDGE OF THE USER}

Rabardel [19] regrets that "the establishment of technical systems favored a techno-centric perspective, in which the machines are in the center and man must adapt his knowledge and even his skills through his work with the machines."

The LKMS chosen must have a socio-constructivist approach. Here the user must have content that his/her likes. That's why it's important to know who is at the center of learning. The new vision places the learner at the center, it is an "anthropocentric" view, which is in line with the pedagogical approach based on skills, knowledge below will help build the structure of the platform:

- Impairment: the training is done by taking into account this factor, the learner has features, such as a dumb will need a course well detailed with video images (sign language), this will not be the case for visually impaired who like to have audio courses.

- Level of study: training is done according to the level of the learner.

A high school student will need an interface containing many images. That is not the case of an university student who will be happy to have more information.

- State of the learner: when connected after a period of time, the learner can doze or be tired. In training room the trainer may ask to stand up. That is not the case for online training. The system will detect inactivity and launch a game, music or an alarm to wake him/her up. Learning through interactive games mobilizes more sensory channels than traditional learning. Learner is attached to the experience, with emotions like fear, satisfaction and the lessons is therefore sustainably store [27].

- Gender: the women will be more happy, to have more vivid colors (pink, green fluorine), and attractive images on their interfaces, to get their attention. This will not be the case for a man who 
just wants an interface with less bright colors (blue, gray). Those aspects are sometimes overlooked, but women are galvanized when the work environment is pleasant.

- Age: The interface of a young that forms online will be different from the one of an old adult. The adult needs a lot of information compared to a young person who wants to have a lot of drawings and pictorial representations.

This knowledge will allow us to direct the man-machine interface of our platform which is nothing else than the entire hardware and software devices enabling a user to communicate with a computer system.

\subsection{General Use CaSeS}

A use case describes the interactions between the system and users. For example the case diagram registration allows use of the learner connects by giving his/her name and surname and all contact information that will enable him/her to present an interface that will be of interest.

It should be recalled that the connection on the platform will always be after authentication.

- The trainer can drop, update or delete a course;

- The learner can read his/her course, do homework and chat;

- The administrator may have the option to delete users or give them certain privileges;

- The visitor meanwhile can only navigate on the platform.

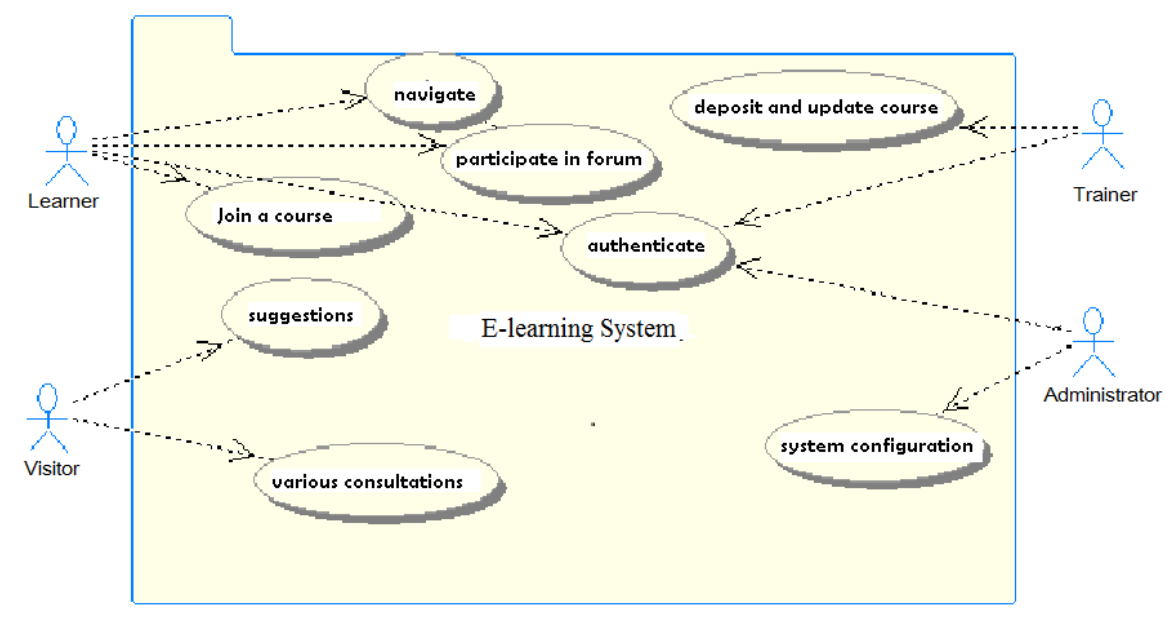

Figure 1. Diagram of utilization case

\subsection{SEQUENCE Diagram}

This diagram shows the set of messages exchanged with the system during interactions of the actor therewith. These digraphs clearly demonstrate interactions between the man-machine interface and users. 


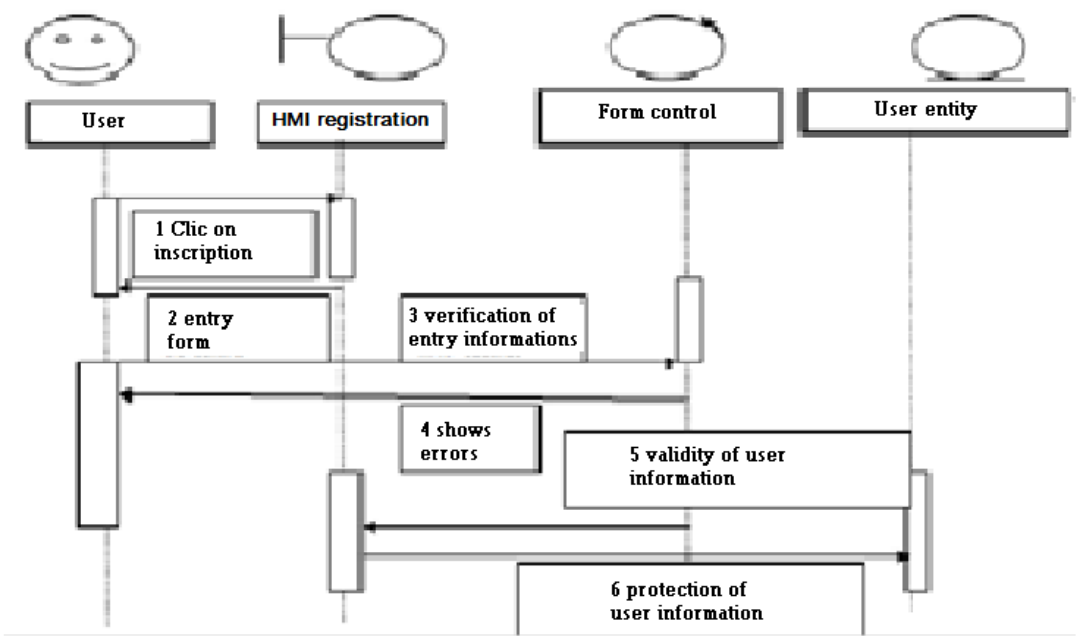

Figure 2. Diagram of registration sequences

This diagram shows when a user registers on the platform, he/she first click on the registration form "registration link", he/she type the coordinates that the system records, in case of error, the system reports that he/she should enter correct information. The system stores all user's data in the class "user" .

Sequence diagram for the case of authentication using successful password, provide the user a background with characters (sizes, colors ) and images at user convenience.

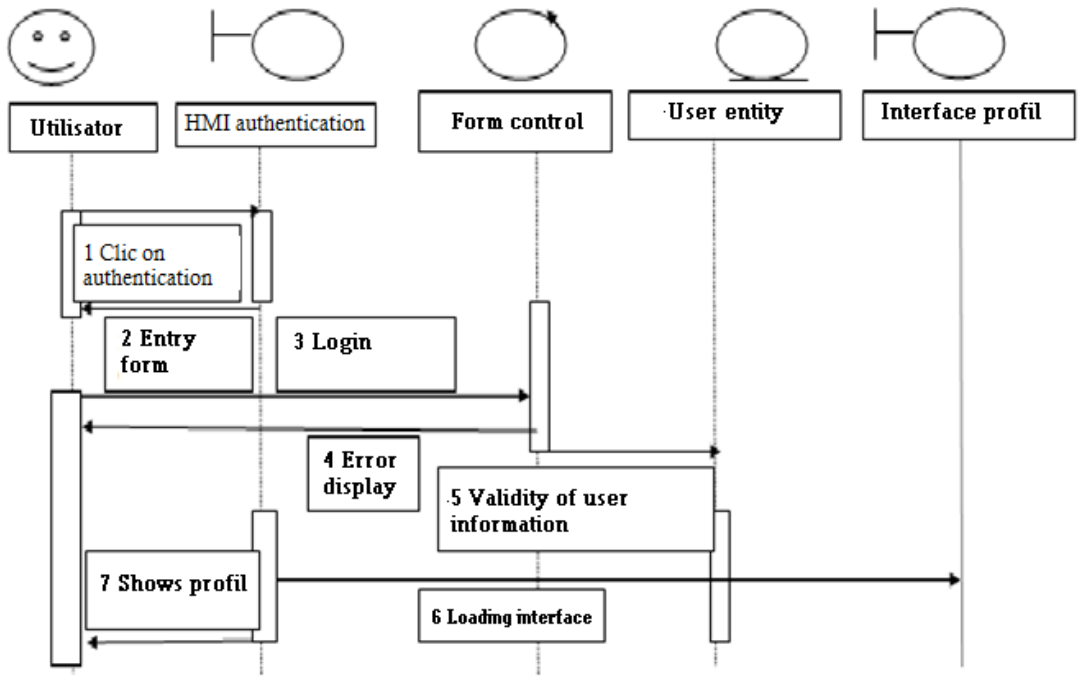

Figure 3. Sequence diagram for authentication

\subsection{Class Diagram}

The class diagram allows to model the entities of the information system. The information is structured class that is an abstract description of a set of objects with common characteristics. The different classes used are: Learner, Trainer, User Courses, Chapter, Homework, Exam Schedule, 
Program Training Administrator. Explanation of terms used in the class diagram. The Knowledge base Management System (KBMS) should handle a volume of persistent data very seriously, and simultaneous access to multiple users. Therefore the concepts used should be explained:

Subject: it's a given to which is attached a set of operations.

Class: it is a collection of objects with common structures and on which the same operations can be done.

Legacy: the potential to create a subclass that inherits from a parent class properties.

Attribute: the property of a class corresponding to a value attached to each instance.

Relationship: it is a relationship between two classes, allowing in any case, knowing a representative of one of two classes, to know, the representatives of the other associated with it.

Cardinality of a relationship: it offers the maximum and minimum number of representations of linked class can be connected to a representative of the class.

Methods: these are the operations defined for all objects of the same class.

- The attributes of learning class are: (username, full name, date of birth, place of birth, disability, degree, level of education, such as, email, nationality). The redirection is automatic when a learner wants to be trained. The administrator will try to see his/her chances to pursue the training and how to be able to fit into working life.

Example: The medical business representative, where you have to be eloquent in order to exercise the profession, if a deaf wants to do this job, it is said that he/she will not be easy to find a job unless he/she goes exercise in an environment where the language of signs is valid. By against a sewing training, agriculture, livestock, ... will not cause him/her any problems in his/her working life. This also justifies the disabled attribute. The study level attribute will help the trainer to design a course according to the level of understanding of the learner.

- The attributes of the current class are: (code, libel, content, beginning, end, head). A course can be done in several ways depending on the learner we have before us; his/her level of understanding. The start date is important because there are short courses and the center is responsible for providing training to follow you sometimes, to reassure you already have or do not know.

- A chapter has attributes that are: (username, libel, content). The same course will be developed in several formats. When the login of the learner, the system chooses the adapted courses. The courses can be audio, video, powerpoint, ... for visually impaired persons who can't read very well.

- Attributes of a trainer are: (username, full name, date of birth, place of birth, specialty, telephone, email). The academic programs are counted over a hundred gradually promising areas will be chosen and open formations when we will realize that there's already people who are trained and failed to find a job is stopped forming in the area.

The knowledgebase must represent at any time as reliable as possible a picture of reality. It is governed by a set of rules, called integrity constraints. In our case we have: 
- Intra-relationship integrity constraints: for example the date of completion of the course, must be a date greater than the start date.

- Inter-relationship integrities constraints: the birth date of the learner, must be less than the start date of the course.

- Behavioural constraints: the case of inheritance link, a learner is a class that inherits a user class. We suppose that a student is removed, there will be no impact on the user class. Contrariwise the deletion of the user class will affect all its subclasses. The composition link between the current class and class assignments stipulates that deleting a course is deleting all assignments attached to it which is not the case for the reverse.

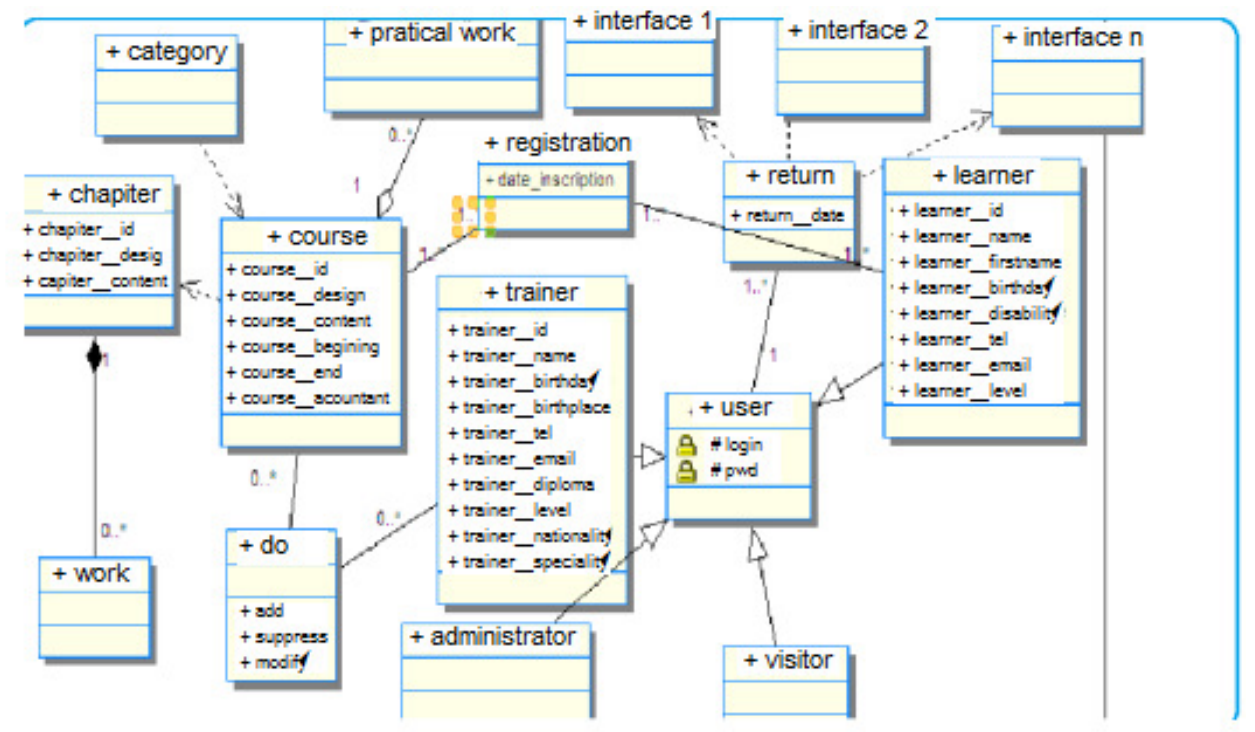

Figure 4. Class diagram

\subsection{RATiOnALE For ARCHiteCtURE}

The architecture we choose is a 3-tier architecture. When the client will send a query to the knowledge base, the expected result is returned to him/her. We will use our knowledgebase to propose a suitable interface to the user according to his/her login informations. The guidance work will be the basis of our work once the learner will connect. If the learner reports hearing loss, his/her interface will have the maximum classes with pictures or video. The chosen architecture is 3-tier client/server, applications at the server level are relocated, to say that each server is specialized in a task (web server and knowledgebase server, for example). Thus, the architecture allows three levels:

- Greater flexibility;

- Increased safety (security can be defined for each service);

- Better performance. 


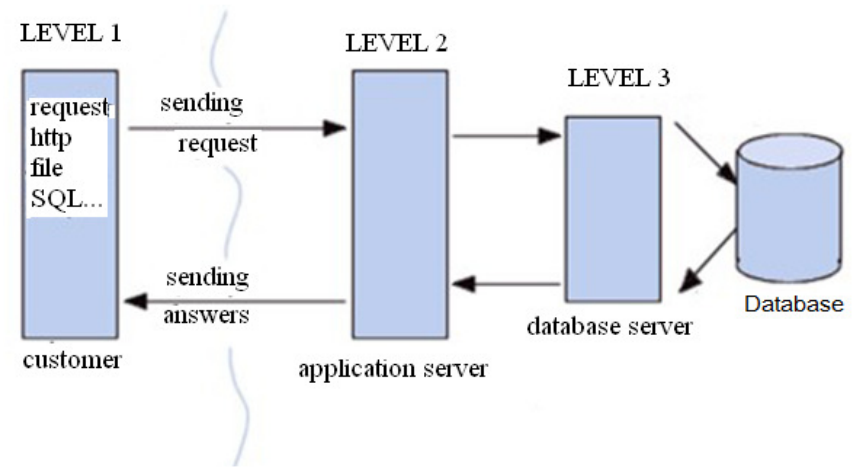

Figure 5. Client / Server architecture [26]

The Web application will have a Web server, which will run PHP code and will interact with the knowledge base server. In that server, all academic programs are located. PHP module returns to the Web server an HTML page for the client display.

The MVC (Model View Controller) architecture is the one that is implemented. The model fits the data stored in a knowledge base. The view shows the Human-Machine Interface (HMI). The controller retrieves information and treats them according to the parameters requested by the view and displays. The advantage of this client/server architecture is that it separates data from view and controller; there's a data independence of the display and actions finally gain a maintenance and evolution of application. The diagram below shows what happens in the background when a user (view) connects and performs an operation, the request is sent to the controller that performs the search based on criteria entered by the user. The model is made of Mysql basic knowledge and is returned to the user expressed needs.

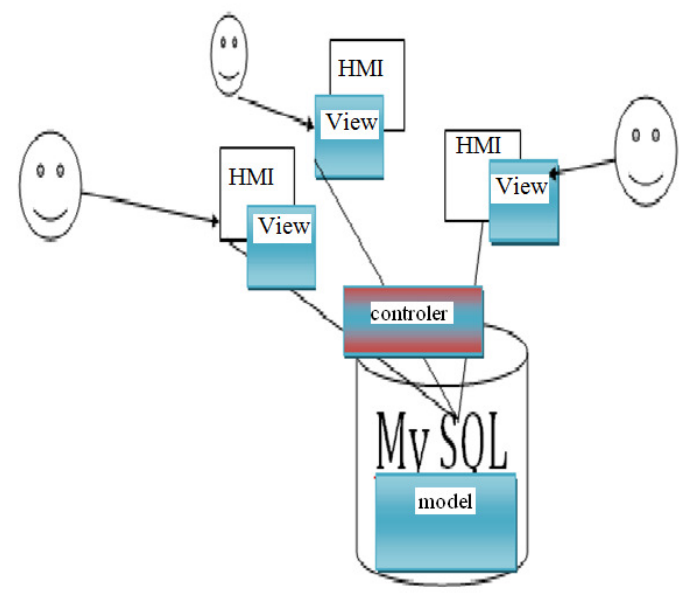

Figure 6. Model View Controller

\section{DEVELOPMENT}

\subsection{Technical Architecture Training Platform}

The general architecture of a training platform such as [SME-Learning 2008] [22] includes: 
- A directory of learning objects to store and classify learning objects;

- A rights management knowledge base of learners and other profiles for storing personal information and educational monitoring data.

- Learners 'knowledge base to monitor learners' records.

- Adaptive System Model (ASM) to adjust the behavior of the system based on preferences and learning styles of learners;

- Login Service to monitor learners' connections and sessions;

- Sequencing and Navigation Module for managing sequencing and tree navigation of the learner;

- Web Server to host all the resources and Internet modules;

- The knowledgebase server (MySQL) for managing knowledge bases.

- Discussion Forum allows learners and trainers to discuss different topics, learning problem FAQ [17]. The next figure presents actors of e-learning platform.

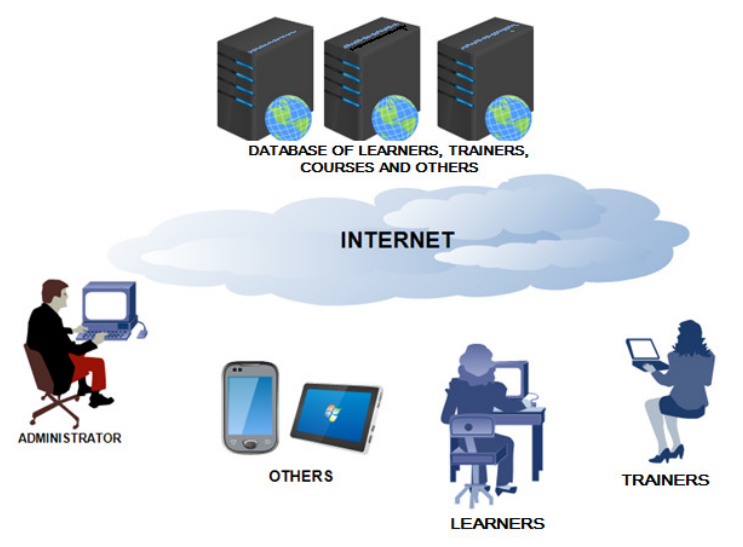

Figure 7. Actors of the training platform

\subsection{HARDWARE AND SOFTWARE TOOLS USED}

Hardware tools used for this work are:

- A computer with an Intel Pentium CPU G 630 processor clocked at 2.70GHZ; an installed memory of $2.0 \mathrm{~GB}$; a 32-bit operating system;

- HP LAZER cl P2055 printer;

- a Nova Avr 1260 inverter.

Software development tools used are:

- Wampserver 2.5 32-bit version, which integrates the (Awareness System Knowledgebase Management)

MySQL 5.6.17, Apache 2.4.9 and PHP5.5.12 as server and host web page.

- Notepad ++ v6.1.4, as a development tool for designing Web pages. 
Advanced Computing: An International Journal (ACIJ), Vol.7, No.4/5/6, November 2016

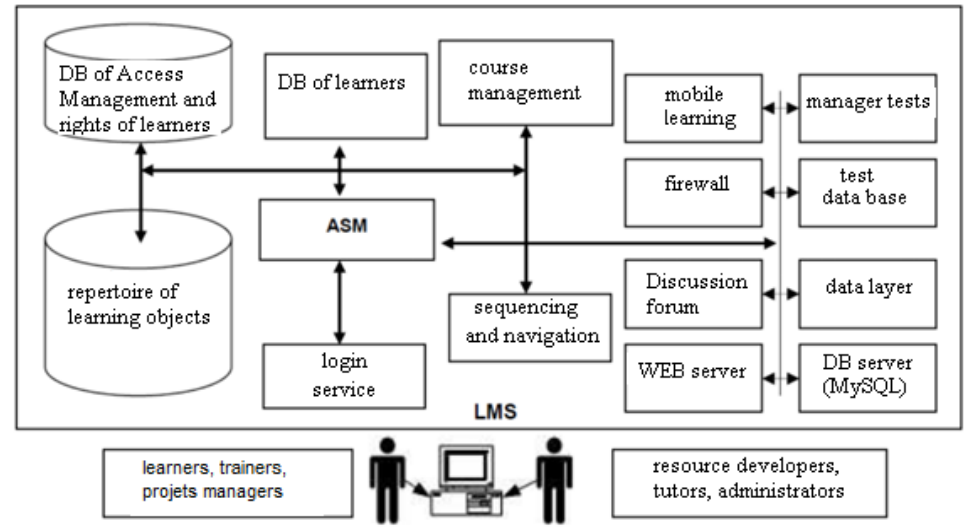

Figure 8. Illustration of Learning Management System (LMS) Architecture

\subsection{Selection Of A Platform}

The platform chosen provide trainers and learners with courses designed by professional of the area aimed at solving these problems. This will allow to retain professional who will seek training on the platform. For that, thanks to online documentations, books and reports dealing with the study of available platforms. We choose from four (4) major platforms including:

- Dockeos : this is a platform for exchange and creation of online courses under the Good Laboratory Practice (GLP) license. It offers many possibilities such as the exchange of documents, participation in a forum, sharing a calendar, chat and conferencing.

Available in several editions: Free, Education, Professional and Medical.

E-Learning Studio offers free resources, templates to quickly create content and develop tests, image galleries. Live collaboration through videoconferencing, monitoring progress of learners, collaborative interactions and time spent learning [5];

- Chamilo: it is an open-source software (under GNU / GPLv3 or later) for learning management and learning content, which aims to improve global access to education and knowledge. It is supported by the Chamilo Association, whose objectives include the promotion of the software, maintaining a clear channel of communication and building a network of service providers and software contributors [3];

- Open Olat: it is a platform developed by the University of Zurich. Originally, it was designed specifically for universities, colleges and academies but nowadays it is also suitable for companies. It is a flexible and user-friendly platform that has been developed in Java and it is optimized for Web 2.0. Its major drawback is its difficulty of implementation because of fairly complex server requirements. It contains an editor that allows the easy creation of OLAT course elements.

- Moodle (Modular Object Oriented Dynamic Learning Environment): it's an open source platform (free license). It is free and widely used but requires accommodation. The accommodation can be done internally or externally. Internally, it involves buying a server, but also skills for installation and maintenance. The server can be hosted externally. 
Moodle runs without modification on Unix, Windows, Mac OS and many other systems that support PHP scripting language and a knowledge base compatible with SCORM and AICC standards.

We propose to use Moodle version 2.4, the preference of Moodle LMS to others is that it is free, it is quite used, it has over ten million $(10,000,000)$ of users in more than two hundred (200) countries and eighty (80) languages, we have the ability to customize it; it is available on a plethora of operating systems: Windows, Mac, Linux. [10]. Here is a view of the base moodle on phpmyadmin which is fully furnished. It is recalled that on the range existing tables, we will add non-existent properties that take into account the physiological characteristics of the user.

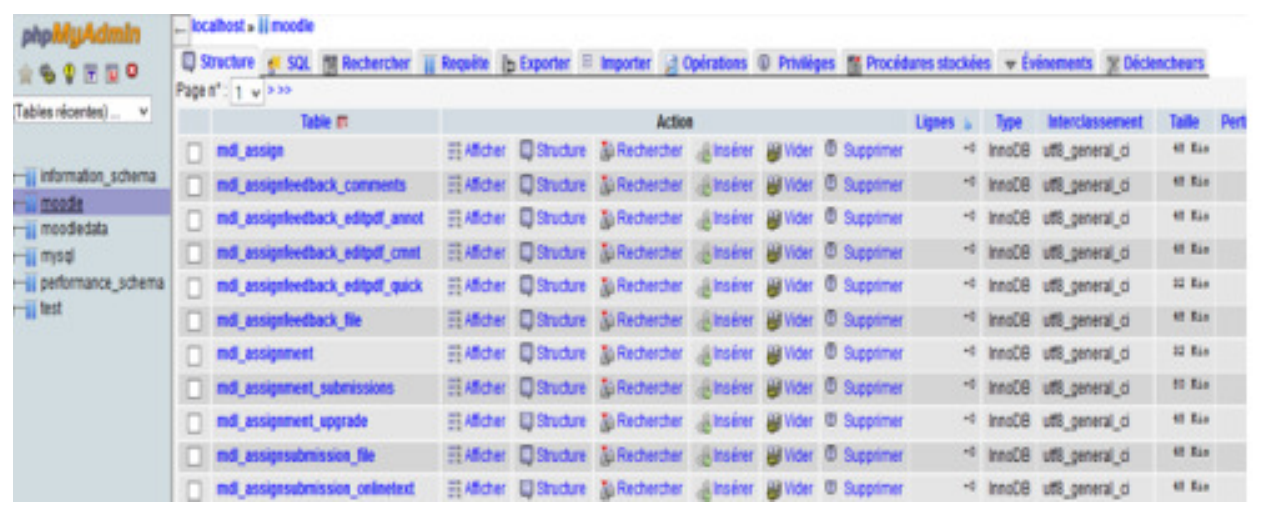

Figure 9. Diagram of the knowledge base architecture

\subsection{Conceptual Architecture Platform}

The man-machine interface presented allows navigation on the platform. The home page allows you to view every interaction on the site, the choice of the user on the link trainer, learner or administrator will request authentication, for the system to verify the user.

When you have not the right to access, the register link enables to enter the information of a new user. The next level allows the learner to carry out his/her activities on a friendly interface. The figure below shows the architecture [30].

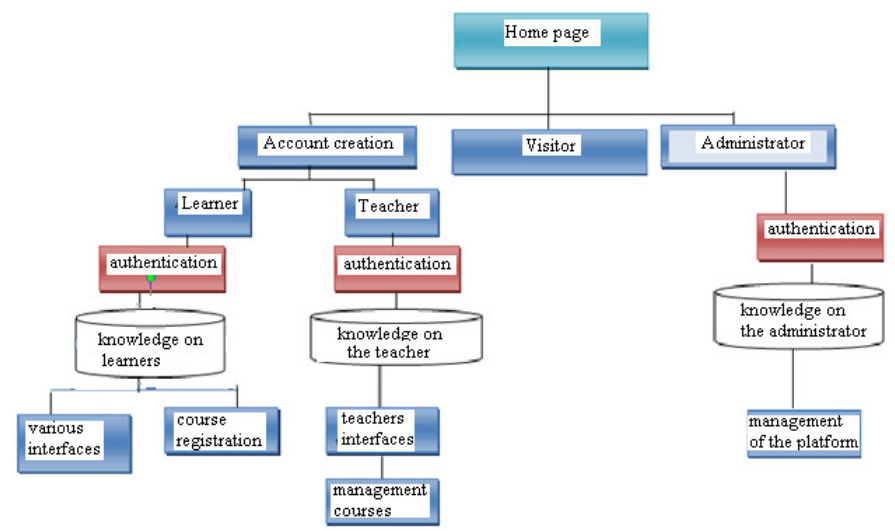

Figure 10. Diagram of the platform architecture 


\subsection{Development OF Modules ANd InTEgration In THE LKMS}

Several training sequences were developed to serve as sample lesson based on the competence approach. These lessons have been developed using the Opal Module 3.5 SCENARIchain 4.1. [20].

SCENARI is an open source application suite for designing and publishing chains, used for creating professional standard multimedia documents. A publishing chain is a technological and methodological process. The publishing chain approach is to create a document model, to make content creation easier and to automate formatting. What is the advantage of a publishing chain? To reduce content production, maintenance costs, and to ensure better quality control. The result of production can be published in many format.

We performed the following tasks:

- Creating training content compatible with SCORM 1.2 and 2004 and broadcast via our platform (LMS) ;

- Facilitate content update with the mechanics of multi- media publishing : a single source of content, several educational materials products;

- Enhance its training content with multimedia resources (videos, sounds, images, explanatory diagrams, ...);

- Enrich its modules with rich educational activities managed automatically by Opal (QCU, multiple choice, closed or open questions).

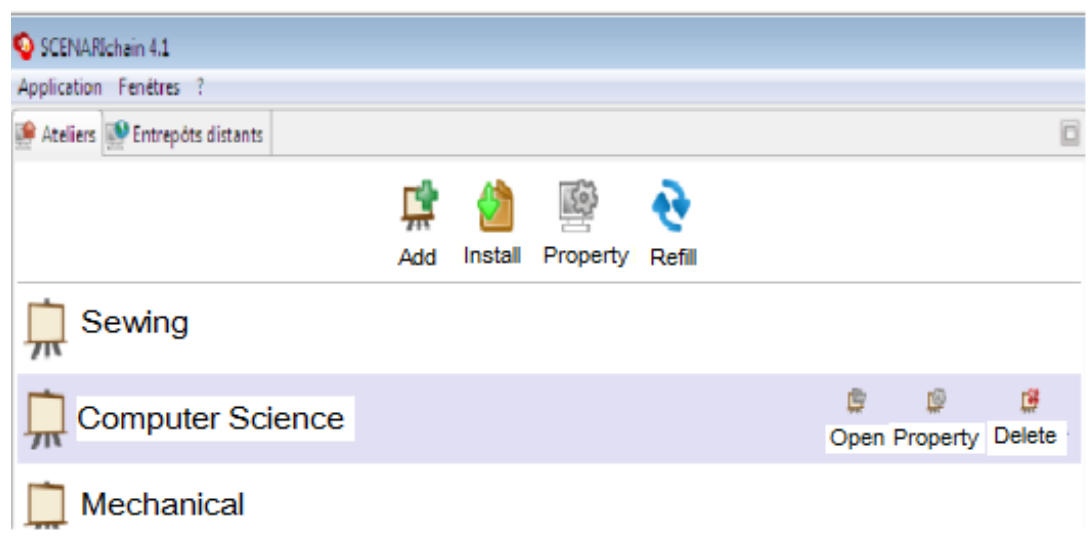

Figure 11. Installation scenarios of successful creation workshops

- Optimize the management and updating of information by creating reusable learning grains from one document to another without duplication, but simply by recombination of content;

- Manage multiple versions of the same module (standard and short version) through a filter system; [6]

After creating a workshop the trainer can create courses. 
Advanced Computing: An International Journal (ACIJ), Vol.7, No.4/5/6, November 2016

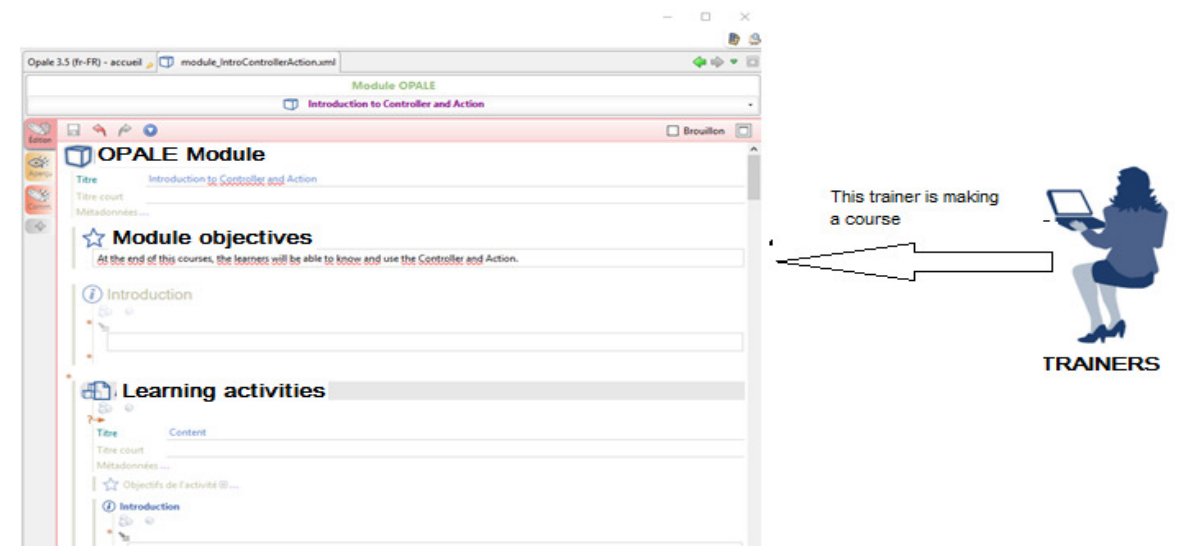

Figure 12. Conception of courses

Then the trainer can publish courses.

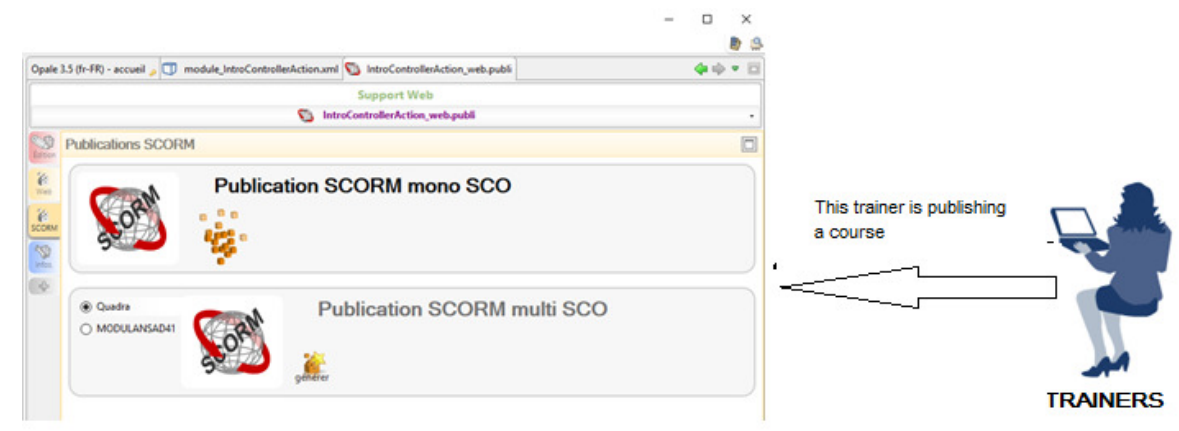

Figure 13. Publishing of courses

\section{IMPLEMENTATION AND DOCUMENTATION}

\subsection{WORKING SESSION ON THE FIELD}

This phase will be the continuation of the previous test and has the objective to present different modules identified in the design phase. We identified bricklaying and carpentry trainers of all Training Centers to explain how the trainers will develop the course. We also do the same pedagogical days for sewing courses. We recall that the competence approach puts the learner at the center of his/her training, learning is iterative hence the design of training reference for each channels.

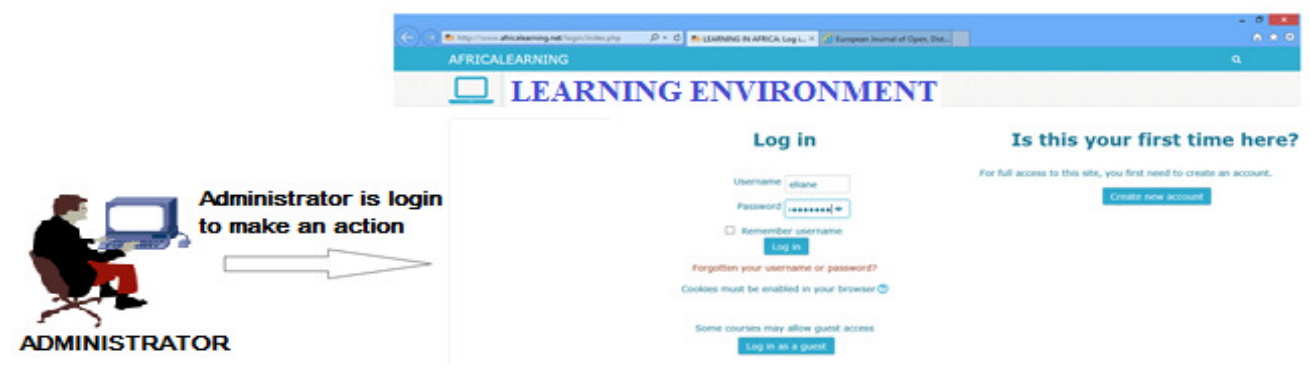

Figure 14. Login of the administrator 


\subsection{Some Screenshots Of The Platform}

A user after finishing his/her work must log out of the system. So, an intruder cannot use his/her session. Once you agree to join the below form with this page. Control is done so that if you are a trainer for a module you cannot be learner for the same module. Trainers forms have features to allow the trainer to insert its current pdf file, audio and video. The learner has the opportunity to connect by providing the user name and password disability, level of study and other settings are already in the knowledge base and redirection is automatic. Moodle logo shows that it is installed and properly configured. After loading courses the learner can connect and read them.

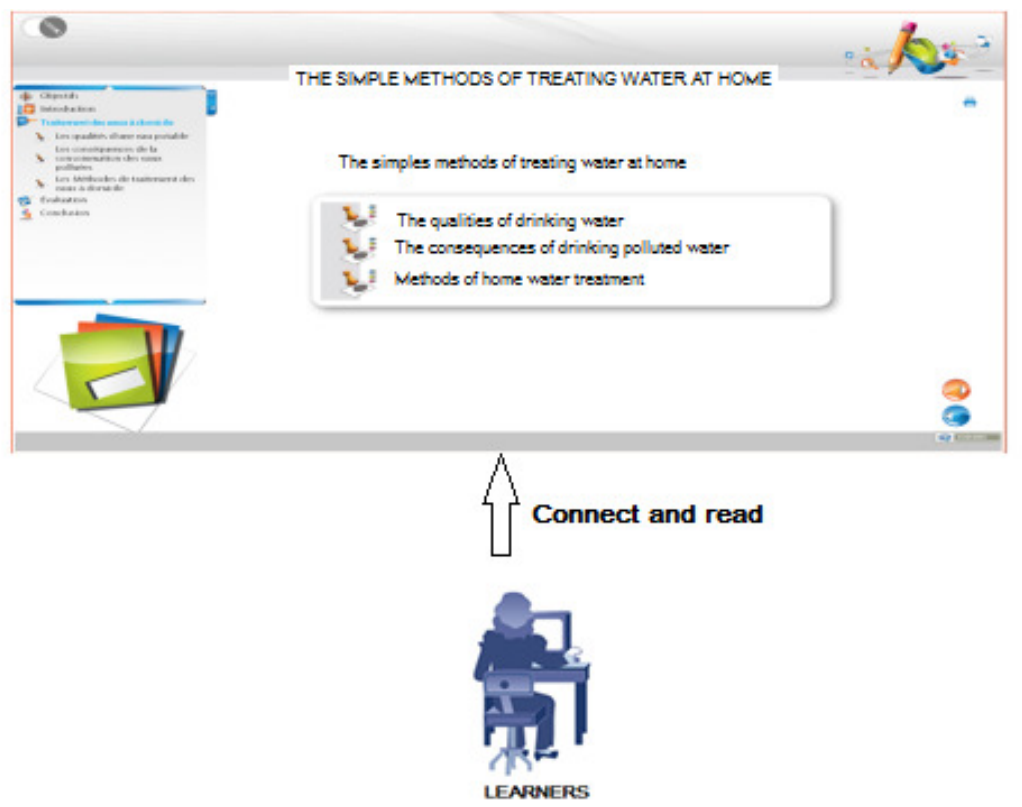

Figure 15. Interface to monitor courses

This evaluation method is designed with opal SCENARIchain module of the suite and integrated in Moodle. The following interface will also be presented in case the learner want to do a test of knowledge .

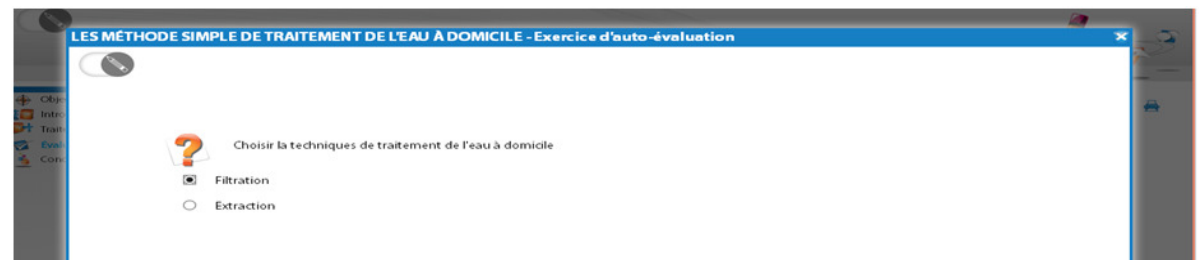

Figure 16. MCQ Lab

The list of participants is recorded and is visible from this screen. For instance, the course on water treatment below can be understood by a deaf mute. 
Advanced Computing: An International Journal (ACIJ), Vol.7, No.4/5/6, November 2016

All partıcıpants: $\circlearrowright$ क

First name : AllABCDEFGHIJKLMNOPQRSTUVWXYZ

Sumame : AllABCDEFGHIJKLMNOPQRSTUVWXYZ

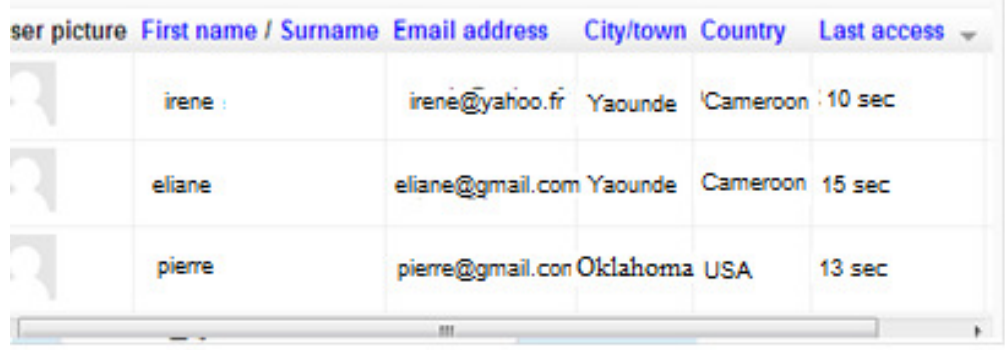

Figure 17. The participants (learners, trainers, administrators)

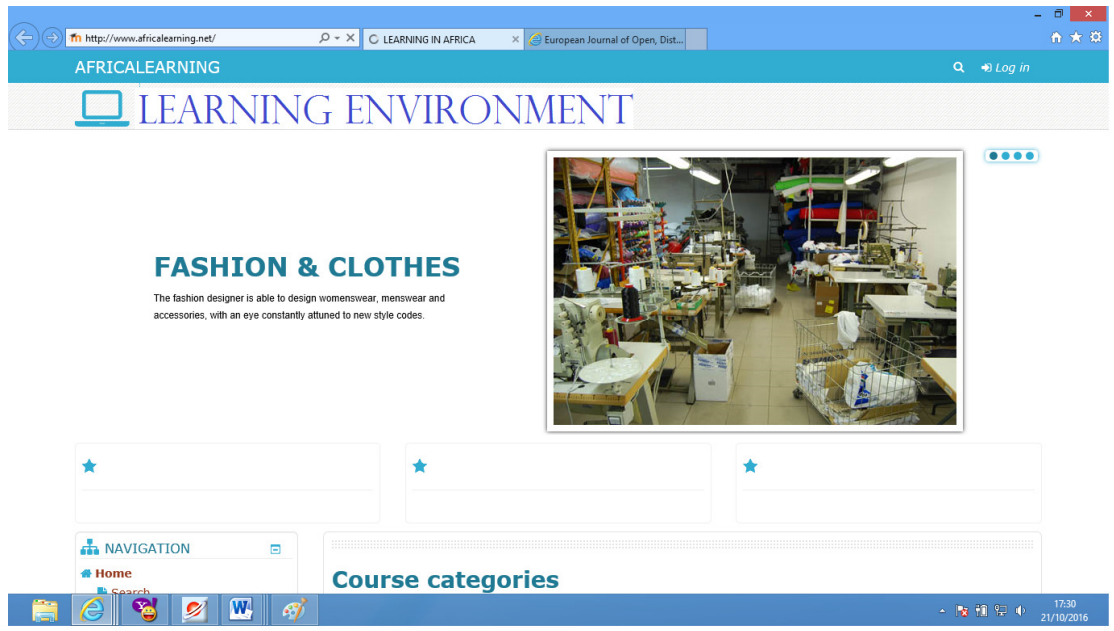

Figure 18. Course developed and put online

\section{Evaluation}

The evaluation was conducted in a developing country with Internet disadvantaged areas. It should be noted that the development of this project was not easy because we had to travel from time to time in professional training centers to access trainers and obtain their views on online training platforms, most had a favorable opinion on the establishment of such a platform. The administration in such developing countries is slow. We have done locally testing and the work was satisfactory. Internet was available on site and we conducted our research throughout our stay.

- Geographical area resident trainers:

It will required working sessions with the actors (trainers, school leaders) in the same sector, to show them that there are tools that allow them to design their courses online and integrate them to the platform;

- Capacity and technical skills of students in information technology: the capabilities and technical skills of information technology in learners varies, they are good for some and bad for others.

- Place where students will attend the course and where they can access the Internet: 
Students will attend classes at home, on campus, in specialized rooms, in offices for workers, in Internet cafes, in short wherever they can have access to the internet.

- Network bandwidth:

The bandwidth used is generally low (for the majority of learners) and is in the range of $24 \mathrm{kbps}$ to $1 \mathrm{Mbps}$.

\section{CONCLUSION AND OUTLOOK}

The objective was to establish a platform for e-learning for all, with interfaces that incorporate knowledge about the user. Now anyone can be trained by the e-learning regardless of disability. We also hope to reduce illiteracy among children who can use our platform. We notice that according to UNESCO, 58 millions of children are not going to school [33]. To reduce unemployment and poverty in the world, the provision of training tools available online, meets the needs of companies to capitalize on knowledge and facilitate their distribution to their employees. They can access according to their needs and their rhythm. Integrate tools of elearning strategy training, is a source of cost reduction and efficiency for businesses. We believe that e-learning with an interface incorporating knowledge about user, is the solution to have a quality education. Online learning has become more accessible for the disabled and even the prisoners.

We initially presented the inventory of e-learning platforms. Then we have built the design of our platform. Our platform was developed, implemented and evaluated. Although we encountered some difficulties during the work.

As perspectives, we will try to solve the case of a learner who combines the evil clairvoyance and deafness. The development of any territory is ensured by men trained in sufficient numbers. As such, the role of e-learning is essential. It is certainly a lever for reducing poverty and raising productivity.

\section{ACKNOWLEDGEMENTS}

The authors would like to thank:

tiakouniversity of Oklahoma;

ENSP of Yaounde I;

University of Yaounde I;

AUF.

\section{REFERENCES}

[1] www.DisabilityStatistics.org consulted in october 2016.

[2] Caron (2007) "Ingénierie dirigée par les modèles pour la construction de dispositifs pédagogiques sur des plateformes de formation". Thesis of doctorat.

[3] Chamilo (2014) http ://edutechwiki.unige.ch/fr/chamilo.

[4] Agence Wallonne des Télécommunications, (2014) " Méthodologie de gestion de projets elearning".

[5] Dockeos (2015) "Récit fga“" http ://recit.qc.ca/dockeos.

[6] Guillemette, François \& Leblanc, Céline \& Char, Lucie (2016) "Direction du soutien aux études et des bibliothèques(DSEB)". Portail du soutien à la pédagogie en milieu universitaire.

[7] Ministère de l'Education Nationale de l'Enseignement Supérieur et de la Recherche (2014) "Portail national des professionnels de l'éducation", France http ://eduscol.education.fr.

[8] Tonye, Emmanuel (2008) "Les tic au service de l'enseignement et de la recherche en Afrique".

[9] Ertoran, Patric (2006) "Les Learning Content Management Systems (LCMS) actualité de la formation permanente 
[10] Labset (2014) "Le portail de la formation à distance en belgique", www.learn-on-line.be/moodle.

[11] Lamiot (2009) "Swot graphefl" wikimedia commons.

[12] Lemadjio, Marlyse (2012) "Plateforme de e-learning avec des interfaces intégrant les connaissances sur les utilisateurs". Master 2, University of Bamenda.

[13] Lewandowsi, Jean-Claude (2003) "Les nouvelles façons de former : le e-learning, enjeux et outils" . Paris : Ed. d'organisation (Regards croisés).

[14] Mar, Vincent (2007) "Le concept d'eleaning", http ://commons.wikimedia.org/.

[15] Marchand, Louise (2003) " E-formation des enjeux aux usages, "Un aperçu de l'état des lieux au canada et au quebec. distance et savoirs.

[16] Tane Nongosso, Duplex (2015) "Plateforme LMS pour l'échange et la collaboration en vue de l'accompagnement et la formation des inspecteurs régionaux, enseignants, futurs enseignants et formateurs de l'inspection de pédagogie chargée de l'enseignement des sciences au Cameroun. " Master 2, online Université de LILLE1 via l'AUF.

[17] Lahcen, Oubasshi \& Nour, EL MAWAS (2004) " Etude comparative des plateformes de formations à distance, " volume GRAPHIT-D2.5 et 2.2. V6.

[18] Piaget, Jean (1923) "Six études de psychologie", Génève, Editions Gonthiers.

[19] Rabardel , Pierre (1995) "Approche instrumentale".

[20] Composants tiers Scenari, (2015) "Scenarichain 4.1", http ://www.scenari-platform.org.

[21] Synteta, P. \& Frété, C. \& Girardin, F. \& Morand, Schneider (2003) "Conception and implementation of rich pedagogical scenarios through collaborative portal sites : clear focus and fuzzy edges." international conference on open and online learning.

[22] SME-Learning (2014). "Guide d'application des tic en formation, " http ://www.smelearning.eu.

[23] Vygotski (1997) "Pensée et Langage", éditions La Dispute.

[24] Wikimemoires (2013) "Les Normes, standards et spécifications du e-learning".

[25] www.awt.be/web/edu/index.aspx?page=edu,fr,gui,080,010. (2016).

[26] www.Commentcamarche.net (2016).

[27] Bruèt, Jérome (2014) "Retenons plus en apprenant avec les jeux, " http ://www.e-doceo.net.html.

[28] Moodle (2016)"About Moodle," Available: https://docs.moodle.org/30/en/Features.

[29] Claroline (2016) "Claroline " Available: https://wikipedia.org/wiki/claroline.

[30] Kouede, Eliane (2015) "Plateforme de e-learning avec les interfaces intégrant les caractéristiques de l'utilisateur" University of Yaounde I, Master II.

[31] Campus Numérique Francophone, (2016) "Le rôle des universités francophones dans le développement économique" Colloque annuel, www.colloqueannuel.auf.org.

[32] UN, (2016) "Sustainable development" http://www.un.org/sustainabledevelopment/fr/objectifs-dedeveloppement-durable/

[33] Figaro (2016) "Formations en ligne" http://etudiant.lefigaro.fr/international/actu/detail

\section{AUTHORS}

Irene Tiako

Researcher at National Advanced School of Engineering of Yaounde, Cameroon and Lecturer at University of Yaounde II, Cameroon. PhD in Computer Science. Area of interest is in E-learning, E-commerce Security and Cryptography, Artificial Intelligence.

\section{Eliane Kouede}

Master Degree of Computer Science and PhD Student in Computer Science, University of Yaounde I, Cameroon. Area of interest is in E-learning, Artificial Intelligence, Internet of Things.

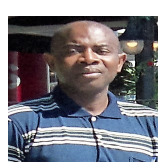

\section{Pierre Fernand Tiako}

Professor \& President, Tiako University, Oklahoma, USA.

Area of interest is in E-learning, Software Engineering, E-Commerce, Social Information Systems, Web Services, Multi-Agent Systems, Cloud Computing

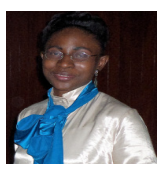

